\title{
The Effect of HRM Attributions on Emotional Exhaustion and the Mediating \\ Roles of Job Involvement and Work Overload
}

\begin{abstract}
Although some research suggests that perceptions of HRM practices are associated with lower levels of employee wellbeing, other research shows just the opposite. In the present study, we attempt to reconcile these discrepant findings by incorporating the role of HRM attributions. Our model posits that when employees perceive that their organisation's HRM practices are intended to improve their job performance, they experience higher levels of job involvement, which leads to lower levels of emotional exhaustion. Conversely, when employees believe that their organisation's HRM practices are intended to reduce organisational costs, they experience work overload, which translates into higher levels of emotional exhaustion. Parallel mediation analyses of survey data collected from employees of a construction and consultancy organisation at two time periods $(n=180)$ supported this theoretical model.
\end{abstract}

Keywords: attributions of HRM practices; emotional exhaustion; job involvement; work overload. 
The relationship between employee perceptions of human resource management (HRM) practices and employee wellbeing remains elusive. Although some research suggests that perceptions of HRM practices are associated with improved employee health and wellbeing (e.g. Harley et al., 2007; Alfes et al., 2012), other studies have revealed that they lead to higher levels of strain and emotional exhaustion (e.g. Sprigg and Jackson, 2006; Jensen et al., 2013). These mixed findings might be explained by the different HRM practices that were measured, different measurements of the same HRM practices, or the manner in which HRM practices are implemented (Boxall and Macky, 2009; Purcell, 1999). We add to this body of literature by examining an alternative explanation for the mixed findings. Specifically, we examine, for the first time, the extent to which employee attributions of the organisation's intent in implementing HRM practices helps to explain the relationship between perceptions of HRM and wellbeing.

HRM attribution theory posits that employees respond to HRM practices based on the attributions they make about the organisation's purpose in implementing HRM practices (Nishii et al., 2008). Unlike prior research on perceptions of HRM that have relied on either employees' descriptions (i.e. does a formal appraisal system exist in my organisation?; e.g. Wright et al., 2005) or evaluations of HRM practices (i.e. is the performance appraisal fair and accurate?; e.g. Alfes et al., 2012), HRM attribution theory stipulates that the effect of HRM practices is determined by the beliefs that employees hold regarding why the HRM practices were implemented in the first place (i.e. why does my organisation use performance appraisals?; Nishii et al., 2008), even though the attributions may differ from the actual or intended organisational or HRM strategy.

We investigate two discrete attributions: (1) HRM-performance attributions refer to employees' belief that the underlying purpose of HRM practices is to maximise employee performance; and (2) HRM-cost attributions refer to employees' belief that the underlying 
purpose of HRM practices is to reduce organisational costs (Nishii et al., 2008). We propose that when employees attribute HRM practices as primarily intended to support their job performance (HRM-performance attributions), emotional exhaustion decreases. Conversely, when employees attribute HRM practices as predominantly aimed at reducing organisational costs (HRM-cost attributions), emotional exhaustion increases. The first contribution of the present study is the use of HRM attribution theory in examining the relationship between perceptions of HRM practices and emotional exhaustion. This study is not only the first to integrate HRM attribution theory and employee wellbeing, but we also address a call to focus on the effect of HRM practices on indicators of employee wellbeing (Moore, 2000; Guest, 2002).

Our second contribution lies in the identification of the mediating processes by which the two attributions of HRM practices lead to emotional exhaustion. Understanding mediating variables is important; Whetten (1989) argued that an essential step in theory building is identifying and examining the underlying mechanism(s) that explain a given relationship. This allows for a richer theoretical evaluation and discussion of why attributions of HRM are important in understanding emotional exhaustion. In our theoretical model, we leverage conservation of resources (COR) theory (Hobfoll, 1989) to suggest that the indirect relationship between HRM-performance attributions and emotional exhaustion operates via job involvement, defined as one's psychological identification with work (Lodahl and Kejner, 1965). Conversely, our theoretical model predicts that the indirect effect of HRM-cost attributions on emotional exhaustion functions through work overload, defined as one's belief that there are insufficient resources with which to perform the job (Beehr et al., 1976). Figure 1 depicts our theoretical model.

We further extend previous findings by using a cross-lagged design. Indeed, conflicting findings with regards to the HRM-employee wellbeing relationship might be 
partially due to methodological considerations (Alfes et al., 2012). As the approach in the present study gathers data across two time points, it reduces concerns related to the "third variable problem" and transient mood states (Cook and Campbell, 1979).

Insert Figure 1 about here

\section{Perceptions of HRM Practices and Employee Wellbeing}

There is a philosophical divide in the field of HRM that is rooted in two opposing perspectives on the role of management vis-à-vis employees (Van de Voorde et al., 2012). Unitarist scholars argue that organisational goals and employee interests are aligned, and that what is good for the organisation is good for the employee. Some research on employee perceptions of high performance work systems supports this premise and shows that HRM bundles increase positive attitudinal and behavioural outcomes, including job satisfaction and performance (e.g. Macky and Boxall, 2007; Alfes et al., 2012; Piening et al., 2013), although there is variation within (e.g. Kinnie et al., 2005; Kooij et al., 2010) and across (e.g. Piening et al., 2014) contexts. Moreover, these bundles are associated with higher levels of wellbeing (Alfes et al., 2012) and lower levels of stress and emotional exhaustion (Kalmi and Kauhanen, 2008). Research that has examined individual HRM practices has likewise shown a positive influence of some HRM practices on indicators of wellbeing. For instance, employees who positively appraise their organisation's selection and performance management system (Harley et al., 2007), who have decision-making autonomy (Harley et al., 2007; Macky and Boxall, 2008), and who can share information with others (Kalmi and Kauhanen, 2008) report less stress or strain at work.

Conversely, the pluralist perspective and labour process theory suggest that there are fundamental differences between the interests of management versus employees. The need for profit overrides employee wellbeing and is traded off in exchange for organisational gain (Godard, 2004; Godard, 2010). From a labour process perspective, HRM practices are 
conceived as managerial control and monitoring tools for increasing employee compliance and performance (Grant et al., 2007). Research that draws from this tradition shows that perceptions of bundles of high performance work systems are positively related to role overload, anxiety, and turnover intentions (Jensen et al., 2013). Research on perceptions of some individual HRM practices, such as the appraisal system and group performance-relatedpay (White et al., 2003), shows that these HRM practices have a negative impact on employees' job-to-home spillover and strain. Moreover, perceptions of intense performance monitoring are positively related to emotional exhaustion, anxiety (Holman et al., 2002), and job-related strain (Sprigg and Jackson, 2006).

Although the mixed results may be partially due to the way in which HRM practices and policies are measured, or in the way in which they are implemented (Boxall and Macky, 2009; Purcell, 1999), in the present study, we offer an alternative way to explain these conflicting findings by leveraging attribution theory (Heider, 1958), and its derivative, HRM attribution theory (Nishii et al., 2008). Attribution theory is concerned with how people attach meaning to external events. Specifically, it posits that individuals respond not to an external event itself, but rather they respond to the event in accordance with why they believe the event occurred.

Nishii et al. (2008: 505) extended attribution theory to the HRM context and argued that employees react to HRM practices "based on the attributions they make about management's purpose in implementing the actual HR practices". The actual strategic intention(s) behind HRM practices are presumably related, at least to some extent, to employees' perceptions of them. However, there is likely to be variability in the attributions that employees make toward HRM practices within an organisation. Just as perceptions of HRM practices are influenced by a number of individual factors and therefore vary within the same organisation (Den Hartog et al., Boselie and Paauwe, 2004), attributions of HRM may 
be the same. Indeed, HRM-attributions are likely influenced by individual-level factors, such as employees' personality and/or the quality of the relationships that employees hold with managers, as they often carry out key HRM activities, such as selection interviews and performance appraisals (Bos-Nehles et al., 2013; Nishii et al., 2008; Purcell and Hutchison, 2007). However, attributions of HRM are different from perceptions of HRM; although employees may share the belief that an HRM practice exists in the organisation, or that it is implemented fairly, they may disagree as to what they believe motivated management to design the HRM practice in first place. According to HRM attribution theory, it is this belief or attribution that is associated with important outcomes (Nishii et al., 2008).

In their initial theoretical development, Nishii et al. (2008) identified five possible attributions, or explanations that employees may have for why HRM practices are in place in the same unionised service organisation: (1) enhancing job quality; (2) improving employee wellbeing; (3) exploiting workers; (4) reducing costs; and (5) complying with union requirements. The results of a confirmatory factor analysis showed that the first two attributions loaded onto one factor, and the second two attributions loaded onto another factor. Hence, Nishii et al. (2008) examined three attributions in their analyses, one that focused on job performance and wellbeing, another on organisational costs and exploitation, and a third on complying with union requirements. Since our sample was a non-unionised private-sector organisation, we chose to focus on variants of the first two (of the three) attributions. Specifically, for the first attribution, we chose to examine the extent to which employees believe that their organisation's HRM practices are designed to increase their job performance. Whereas Nishii et al. (2008) focused on "quality" as a measure of performance, we chose to use the broader term, “job performance,” because in our sample organisation, job performance encompasses more than quality. For the second attribution, we focused on employees' perception that the organisation's HRM practices were designed to reduce 
organisational costs. Hence, we examine HRM-performance and HRM-cost attributions. Although these may not be the actual intentions of the organisation's strategy (and indeed, often increasing performance and reducing costs may be two parts of the same organisational strategy), they describe employees' attributions of why the organisation implements HRM practices. It is important to note that HRM attributions are discrete categories; theoretically, employees may attribute HRM practices as designed to increase their performance and decrease organisational costs.

A small body of research has begun to show that attributions of the organisation's intent in developing and administering HRM practices play an important role in determining employee outcomes (e.g. Fontinha et al., 2012; Mignonac and Richebé, 2013). While these studies investigated the effect of HRM attributions on attitudinal and behavioural outcomes, we contribute and build on these studies by examining HRM attributions in relation to an indicator of employee wellbeing, that is, employee emotional exhaustion.

Understanding the HRM factors that are associated with emotional exhaustion is important because employees who are emotionally exhausted are prone to ill health, reduced performance, and increased absenteeism and turnover (e.g. Cropanzano et al., 2003; Grandey et al., 2004; Podsakoff et al., 2007). Moreover, we focus on emotional exhaustion as an indicator of wellbeing because emotional exhaustion is a focal construct in COR theory, which we use to support the following mediation hypotheses.

\section{HRM-performance Attributions, Job Involvement and Emotional Exhaustion}

According to COR theory, people are motivated to obtain, protect, and retain important tangible (i.e. money) and intangible (i.e. social support) resources; the accumulation of resources enables people to invest and re-invest resources in their work. Indeed, employees who receive resources from their work environment are capable of 
investing their energies into, and identifying with their work, compared to those who are situated in resource-poor environments (Gorgievski and Hobfoll, 2008; Hobfoll, 1989).

Employees who believe that their organisation's HRM practices are designed to increase their performance positively interpret their organisation's intent in developing and administering HRM practices (Nishii et al., 2008) and therefore signal to employees that they are important and valuable, and that the organisation believes in their ability to perform. This perception provides employees with resources that enable them to fully embrace their role. For instance, HRM-performance attributions may provide personal resources to employees, as they lead employees to feel adept at work and able to meet workplace demands. As a result, they are likely to view their contributions as meaningful (Chen and Chiu, 2009). Hence, in line with COR theory, HRM-performance attributions foster employees' perceptions that they receive the necessary support and resources to perform at high levels. This in turn may lead to job involvement, or the psychological identification with one's job (Lodahl and Kejner, 1965).

According to COR theory, employees experience emotional exhaustion when they have depleted resources, including a lack of energy resources (Hobfoll, 1989; Hobfoll and Freedy, 1993; Gorgievski and Hobfoll, 2008). Gorgievski and Hobfoll (2008) theorized that energy resources at work might take the form of work engagement or flow, concepts that are similar to involvement. They added that positive psychological states such as these should be inversely related to emotional exhaustion. Prior researchers have leveraged COR theory to understand the effect of positive job attitudes, including job involvement, on emotional exhaustion. Indeed, research shows that employees who enjoy positive work-related attitudes, such as job involvement, are more motivated at work, and hence may overcome obstacles more easily (e.g., Brown and Leigh, 1996). Moreover, prior research has shown that employees who are involved in their job have plentiful supportive resources, such as 
feedback from the job (Hassan, 2012) and opportunities for development (Maurer et al., 2003). According to COR theory, those with more resources are less vulnerable to resource loss, and are more capable of resource gain, and are therefore less likely to experience emotional exhaustion. Parasuraman and Alutto (1984) suggested that job involvement diminishes role frustration and tempers the effects of stressful working conditions. This argument is consistent with research that has revealed that job involvement is negatively related to emotional exhaustion (e.g. Elloy et al., 1991; Paoline and Lambert, 2011). These propositions culminate in a mediation hypothesis. In other words, we expect that the indirect effect of HRM-performance attributions on emotional exhaustion operates through job involvement. We therefore hypothesise:

Hypothesis 1: HRM-performance attributions is positively related to job involvement.

Hypothesis 2: Job involvement is negatively related to emotional exhaustion.

Hypothesis 3: Job involvement mediates the relationship between HRM-performance attributions and emotional exhaustion.

\section{HRM-cost Attributions, Work Overload and Emotional Exhaustion}

Employees who believe that HRM practices exist to reduce costs infer that the organisation is interested in minimising spending by withholding resources and increasing demands. These attributions may lead to perceptions of work overload, which is associated with unachievable deadlines, working intensely, time pressures and conflicting commitments (Beehr et al., 1976; Jensen et al., 2013). HRM-cost attributions imply that employees perceive a lack of supportive HRM resources, as resources are costly for the organisation; hence employees believe that they are expected to do more with less (Kelliher and Anderson, 2010). Employees who attribute minimising costs as the underlying motive for HRM practices may view these practices as an attempt to increase the pace of work in order to extract more value from them. In line with COR theory, HRM-cost attributions create a 
negative work environment where employees perceive their work as overloaded, and therefore they need to invest additional physical or psychological resources to maintain performance. Their resources become drained as a consequence of work overload.

COR theory predicts that the perception of work overload leads to emotional exhaustion. Indeed, the theory states that exhaustion occurs when people engage in a situation in which they need to invest more resources than they receive, such that there is a net loss. Exhaustion also may occur when many resources must be put into place to prevent resource loss. An employee who feels overloaded will try his or her best to manage the demands by putting in additional time and energy to perform in such an environment; the use of this extra time and energy can result in feelings of emotional exhaustion when the employee's time and energy supply is depleted (Hobfoll, 1989)

This is corroborated by prior research which has shown that employees who are overburdened at work experience heightened stress levels (e.g. Burke et al., 2010), job strain (Landsbergis et al., 1999; Jensen et al., 2013), emotional exhaustion (Maslach et al., 2001), and even increased physical pain (Oxenbridge and Moensted, 2011). Taken together, employees who perceive that the organisation's HRM practices are designed to reduce costs feel overburdened with work, leading to distress, or in other words, we expect that the indirect effect of HRM-cost attributions on emotional exhaustion operates via work overload. We therefore hypothesise:

Hypothesis 4: HRM-cost attributions is positively related to work overload.

Hypothesis 5: Work overload is positively associated to emotional exhaustion.

Hypothesis 6: Work overload mediates the relationship between HRM-cost attributions and emotional exhaustion.

\section{Method}

\section{Sample and Procedure}


The criteria according to which we chose a participating organisation was that it had a relatively stable yet active set of HRM practices such that employees have an understanding of the HRM practices in place. The HRM manager stated that employees likely make attributions regarding HRM policies and practices and would be able to do so because the HRM policies and practices are visible in the organization; for instance, the organisation has an extensive intranet where HRM-related information is shared and regularly updated, there is a strong culture of onboarding/induction where employees are able to familiarize themselves with HRM practices, and the HRM department initiates regular, visible initiatives within the organisation. An additional criterion was that the organisation would allow us to administer two surveys.

A construction and consultancy organisation in the United Kingdom (UK) matched these criteria. The organisation offers integrated services across the property and infrastructure life cycle. It employs over 4,000 employees who work on construction and consultancy projects. For instance, their work involves project management, construction delivery, and facilities management across the arts, education, utilities, sport, technology, and transportation sectors. The HRM manager stated that the type of work carried out by employees has the potential to be exhausting for them.

The HRM department asks its employees to complete a number of surveys throughout the year. The HRM manager selected three divisions to be included in our study so as to minimise survey fatigue. We have labelled the Divisions: A, B, and C. Each division conducted construction business in a different sector. All 671 employees who worked in these three divisions were invited to complete an online survey in the autumn of 2010. Participants were asked to answer questions that measured HRM attributions. In developing the survey, we incorporated procedural remedies to minimise contamination due to common method bias 
(Podsakoff et al., 2003). Four hundred and fourteen surveys were completed, constituting a response rate of $62 \%$.

Twelve months later, all employees who participated in the first survey were invited to take part in the second survey, following the same procedures used for the first survey. Employees responded to statements that measured job involvement, work overload, and emotional exhaustion. One hundred and eighty employees completed the second survey, constituting a response rate of $43.5 \%$. In the final sample, $42 \%$ were female, the average age was 42 years $(\mathrm{SD}=15.64)$, and $50.1 \%$ of the sample held a management position. The average tenure was 4 years $(\mathrm{SD}=3.99)$.

\section{Measures}

All items for all scales were scored on a 1 (strongly disagree) to 7 (strongly agree) scale. Scale reliabilities are found in Table 1. The items that were used to measure the study variables are found in Appendix 1.

\section{Insert Table 1 about here}

Human Resource Management Attributions were measured by two variables, HRM-performance and HRM-cost attributions. In selecting the individual HRM practices, we liaised with the HRM manager to ensure that the individual practices were reflective of the organisational context. We selected HRM practices with theoretical precedence, including training and development, selection processes, and reward systems, as used by Nishii et al. (2008). In addition, the HRM manager recommended that we include "performance appraisal" and "employee participation" as these practices were salient in the organisation. The employees responded to five questions about HRM-performance attributions and five questions about HRM-cost attributions.

We carried out an exploratory factor analysis on the ten attribution items, using the principal components procedure with varimax rotation in SPSS.21. The rotated solution 
showed that all items for HRM-performance attributions loaded onto one factor, whereas all items for HRM-cost attributions loaded onto a second factor. There were no items with crossloadings. These results show that the items loaded by attribution and not by HRM practice, and demonstrate that employees attributed all five HRM practices to the same underlying HRM intent. In addition, we carried out a confirmatory factor analysis to examine whether the two HRM attributions were distinct. Specifically, the five items for HRM-performance attributions were loaded onto one factor, whereas the five items for HRM-cost attributions were loaded onto a second factor. The results revealed an acceptable model fit. Specifically, the $\chi 2$ df ratio was lower than 3 , indicating a good fit (Arbuckle, 2006); the IFI value was .90, indicating a good model fit (Bollen, 1989, Marsh and Hau, 1996); the SRMR value was .08, indicating a reasonable fit (Hu and Bentler, 1998). The RMSEA value was .10, which is considered the upper acceptable level (MacCallum et al., 1996). Finally, the CFI value was .90 , which is below the recently advocated cut-off point of .95 , but still at an acceptable level (Bentler, 1990; Hu and Bentler, 1999). Hair et al. (2009) have argued that it is important to assess model fit using different fit statistics simultaneously. As the majority of fit indices are in line with recommended cut-off criteria, we considered the model fit to be acceptable overall. Importantly, the correlation between the two attribution factors was not significant. We compared the two-factor model with a one-factor model, where all items were loaded onto one factor. The one factor model had a very poor model fit $\left(\chi^{2} / d f=10.14 ; \mathrm{CFI}=.49\right.$; $\mathrm{IFI}=.50 ; \mathrm{RMSEA}=.23 ; \mathrm{SRMR}=.20$ ), lending support to the notion that HRM-performance and HRM-cost attributions are distinct factors.

An independent samples $t$-test showed that participants who completed the first survey $(\mathrm{M}=4.56, \mathrm{SD}=1.07)$ did not differ in their response to HRM-performance attributions compared to those who completed both surveys $[\mathrm{M}=4.55, \mathrm{SD}=1.01 ; t=.15, p=.88]$. Likewise, perceptions of HRM-cost attributions did not differ between participants who completed the 
survey at time 1 only $(\mathrm{M}=4.18, \mathrm{SD}=.99)$, versus those who completed both surveys $[\mathrm{M}=4.07$; $\mathrm{SD}=1.04 ; t=1.14, p=.26]$.

We transformed each HRM attribution by creating, from the 7-point scale, a low (from 1.0 to 2.33 ), medium (from 2.34 to 4.66 ), and high (from 4.67 to 7.0 ) category for each HRM attribution. The results showed that for HRM-cost attributions, $6.1 \%$ of the sample had low levels, $70 \%$ had medium levels, and $23.9 \%$ had high levels. For HRM-performance attributions, $3.3 \%$ of the sample had low levels, $51.7 \%$ had medium levels, and $45 \%$ had high levels. The continuous form of the variable was used to test the hypotheses.

Job Involvement was measured with a nine-item version of Lodahl and Kejner's (1965) 20-item scale. Brown (1996: 236) stated, "in practice, users of [this] scale have usually employed shortened versions of it" because it reduces the conceptual ambiguity with some aspects of the longer scale, and best represents the psychological identification that employees have with their job. Generally, the shortened version contains six-items; in our study we included three additional items as the HRM manager believed these would be applicable to the organisation.

Work Overload was measured with a six-item scale used by Macky and Boxall (2008).

Emotional Exhaustion was measured with three items from Maslach and Jackson's (1981) scale, as used by Hülsheger et al. (2013; Study 1; second measure).

Control Variables. Variables that have the potential to covary with emotional exhaustion (Becker, 2005) include gender (1 if female; 0 if male), age, and whether a person has managerial responsibilities ( 1 if manages others; 0 if does not manage others; e.g. Wright and Bonnett, 1997; Lindert et al., 2009; Kenworthy et al., 2014). We conducted a series of one-way ANOVAs to determine whether any of the study variables differed by division 
within the organisation. The only significant finding was HRM-cost attributions. Hence, we controlled for division in all of the analyses (division $\mathrm{C}$ is the comparison group).

\section{Statistical Examination of Common Method Variance}

We followed Podsakoff et al.'s (2003) suggestion to examine the pervasiveness of common method variance using statistical methods. Specifically, we tested a full measurement model, in which the indicators for all variables were allowed to load onto their respective factors. All factors were allowed to correlate. In the measurement models, error terms were free to covary between two pairs of job involvement and one pair of work overload items to improve fit and help reduce bias in the estimated parameter values (Reddy 1992). The fit of this five-factor model to the data was reasonably good $\left(\chi^{2} / d f=1.78\right.$;

$\mathrm{CFI}=.90 ; \mathrm{IFI}=.90 ; \mathrm{RMSEA}=.07 ; \mathrm{SRMR}=.08$ ). To establish the discriminant validity of the scales, we compared the five-factor model with five alternative solutions, as indicated in Table 2. The model fit of these alternative models was significantly worse. Therefore, our findings suggest that common method variance does not wholly explain the associations found in the data.

Insert Table 2 about here

\section{Results}

\section{Descriptive Statistics and Intercorrelations}

Table 1 provides descriptive statistics, scale reliabilities, and intercorrelations among all variables. It is noteworthy that HRM-cost attributions was not significantly correlated with work overload. However it should be noted that the correlation was approaching significance $(p=.06)$.

\section{Tests of Hypotheses}

The hypotheses were tested using Hayes' (2013) "process" macro in SPSS.21. This approach to mediation is preferred to more traditional approaches to mediation (e.g. Baron 
and Kenny, 1986), as it does not require a normal sampling distribution. The approach draws on ordinary least squares regression to estimate direct and indirect effects of mediation and uses 1000 bias corrected bootstraps. Since our theoretical model implies that the two mediators are not interchangeable, we estimated two parallel dual mediator models to test the hypotheses, with job involvement and work overload modelled as mediators. Tables 3 and 4 present the results of the hypotheses testing.

The results of Table 3 show that HRM-performance attributions is positively related to job involvement, but not work overload, and job involvement is negatively related to emotional exhaustion. Moreover, HRM-performance attributions had a direct effect on emotional exhaustion, while controlling for the control variables only. Hypotheses 1 and 2 are therefore supported.

\section{Insert Table 3 about here}

Next, we conducted a test of direct and indirect effects to test whether job involvement mediates the relationship between HRM-performance attributions and emotional exhaustion. The results of the direct effect of HRM-performance attributions on emotional exhaustion was not significant $[B=-.05, S E=.10 ; C I(-.25, .14)]$ when job involvement and work overload were statistically controlled. The indirect effect of HRM-performance attributions on emotional exhaustion via job involvement was significant $[B=-.18, S E=.05 ; C I$ (-.28, -.09)], whereas the indirect effect HRM-performance attributions on emotional exhaustion via work overload was not significant $[B=-.07, S E=.07 ; C I(-.22, .05)]$. These results support Hypothesis 3. Of additional interest is that work overload did not mediate the relationship between HRM-performance attributions and emotional exhaustion.

We carried out the same procedures to test Hypotheses 4 and 5. The results displayed in Table 4 show that HRM-cost attributions was positively related to work overload and work overload was positively related to emotional exhaustion. Hypotheses 4 and 5 were supported. 
The results also showed that HRM-cost attributions was not significantly related to job involvement, nor was it related to emotional exhaustion while controlling for the control variables only.

Insert Table 4 about here

In a test of hypothesis 6, the results of the direct effect of HRM-cost attributions on emotional exhaustion was not significant $[B=-.08 S E=.09 ; C I(-.26, .11)]$, when job involvement and work overload were statistically controlled. The indirect effect of HRM-cost attributions on emotional exhaustion via work overload was significant $[B=.10, S E=.05 ; C I$ $(.01, .21)]$, whereas the indirect effect of HRM-cost attributions on emotional exhaustion via job involvement was not significant $[B=-.03, S E=.04 ; C I(-.11, .05)]$. Hence, work overload (and not job involvement) mediated the relationship between HRM-cost attributions and emotional exhaustion, thereby supporting Hypothesis 6.

\section{Discussion}

A pressing question for both the scholarly and practitioner HRM communities is whether HRM practices facilitate or inhibit employee wellbeing. Rather than merely reexamining the relationship between employees' descriptions or evaluations of HRM practices and emotional exhaustion, the present study drew from the work of Nishii et al. (2008) to investigate the extent to which this relationship can be explained by employees' attributions of organisational intent in the design of HRM practices. The results showed that employees who believe that their organisation's HRM practices are designed to increase performance reported lower levels of emotional exhaustion via job involvement, whereas those who believed that HRM practices were intended to reduce organisational costs reported an increase in emotional exhaustion via work overload. In other words, emotional exhaustion is a function of employees' perceptions regarding why the organisation implemented its HRM practices. This is the first study, to our knowledge, to apply HRM attribution theory to 
employee wellbeing. Hence, the first contribution of the present study lies in the use of Nishii et al.'s (2008) HRM attribution model to explain divergent findings in the literature.

Relatedly, our study contributes to the perceptions of HRM literature because it focuses on employee wellbeing, a relatively neglected topic. Although research on attributions of HRM is on the rise, it has focused on its association with job and organisationrelated attitudes and behaviours. Guest (2002) argued that it is time to bring the employee to the forefront of discussions of HRM theory. Indeed, the dominant unitarist focus has tended to either marginalise 'softer' outcomes, such as wellbeing, or has focused on how the organisation may gain from them (Van Buren et al., 2011; Truss et al., 2013). Instead of focusing on performance outcomes, we investigated an outcome pertinent to employee wellbeing, namely emotional exhaustion. In addition, by considering attributions we acknowledge that employees play an active role in interpreting their environment as opposed to being passive entities whereby HRM is "done" to them.

The second contribution of the present study is that we examined mediators of the relationship between HRM-performance and HRM-cost attributions and emotional exhaustion. This is important as it helps to build robust theories on why certain outcomes (e.g. an increase in emotional exhaustion) follow perceptions of HRM practices. By applying COR theory and elucidating the mediating variables in the relationship between HRM attributions and emotional exhaustion, we show that these attributions impact on emotional exhaustion via job involvement and work overload.

A finding of interest in the present study is that the direct relationship between HRMcost attributions and emotional exhaustion was not significant. Although the traditional approach to examining mediation requires that the independent variable is significantly correlated with the dependent variable (e.g. Baron and Kenny, 1986), contemporary organisational statisticians argue that this step is not necessary because in some cases, it is 
only possible to understand the effect of the independent variable on the dependent variable by taking the mediator into consideration (e.g. Hayes, 2013). This finding signifies the importance of COR theory in unravelling these relationships. Indeed, employees who viewed their organisation's HRM practices as a means to reduce costs had higher levels of emotional exhaustion due to work overload. The present study therefore contributes to building theory in this area by highlighting the importance of COR processes in understanding the relationship between both HRM-cost and HRM-performance attributions and emotional exhaustion.

Our research findings are suggestive of several avenues for future research. The nearzero correlation between HRM-performance and HRM-cost attributions (see Table 1) indicates that intra-organisational factors influence employees' (who work for the same organisation) attributions of HRM practices. Future research should therefore investigate factors such as employees' personality (i.e. neuroticism or core-self-evaluations) and the quality of employees' relationships with their managers, as there is theoretical reason to believe that each may influence attributions of HRM practices (e.g., Folger and Skarlicki, 1998; Judge et al., 2000; Bos-Nehles et al., 2013; Purcell and Hutchison, 2007).

The probable association between HRM attributions and line management attitudes and behaviour should be prioritised in future research. This is because an alternative explanation for our findings is that HRM attributions are merely a proxy for leader-member exchange, or the quality of employees' relationship with their line manager (Graen and UhlBien, 1995). Indeed, as line managers today implement an increasing number of HRM practices (Guest and Bos-Nehles, 2013; Purcell and Hutchison, 2007), the attributions that employees make of the HRM policies and practices may be coloured by the relationships that employees hold with their manager. Research also shows that line managers have the potential to influence employees' wellbeing (Lee and Ashforth, 1996). Future research is 
therefore needed on the relationship between attributions of HRM and leader-member exchange quality.

Future research should also examine inter-organisational factors that may influence employees' attributions of HRM practices. Our study was tested within a single organisation. Hence, we were unable to test for inter-organisational factors that may explain variation in attributions of HRM. Doing so is important because the wider context within which organisations operate likely influences not only the effectiveness of HRM practices (Paauwe and Boselie, 2003), but also employees' attributions of them. For instance, the country or sector in which the organisation operates may influence the type of attributions made by employees about the HRM system. Moreover, factors related to the organisational context, such as the size or age of the organisation, labour turnover, and also its strategy and corporate culture might likewise influence employees' attributions of HRM practices. For example, in an organisation characterised by a participative leadership culture, employees may be more likely to make positive attributions about HRM practices.

Although our study used a cross-lagged design, we did not test our model longitudinally. This might be critical in the development of HRM attribution theory, as HRM attributions may be influenced by employees' work-related experiences. In terms of the model presented in this study, there may be a feedback loop between emotional exhaustion and either of the HRM attributions. Likewise, job involvement or work overload may in turn influence employees' attributions of HRM practices. Future research should control for the dependent and mediating variables at time 1 in order to partial out the stable effects that are associated with the criterion. Three or more waves of data collection would permit the examination of these relationships through growth curve modelling.

The finding that job involvement was negatively related to emotional exhaustion is also notable. Although some research, like ours, has found a negative relationship between 
the two (Elloy et al., 1991; Paoline and Lambert, 2011), other research has found a curvilinear relationship between job involvement and burnout, such that at very high levels of job involvement, employees become exhausted at work (e.g. Snir and Harpaz, 2012). To examine this potential in our data, we conducted a post hoc analysis. The result of the quadratic term for job involvement was not significant $(B=-.07, S E=.05, p=.21)$. Nonetheless, we encourage future research to examine a curvilinear relationship between job involvement and burnout, paying particular attention to employees who are highly involved with their job, but who lack organisational support. Morin et al.'s (2013) findings are of interest in this context; they found curvilinear relationships between commitment (to the organisation and clients) and burnout, such that at very high levels of commitment, there were increasing levels of burnout.

\section{Limitations}

Although our cross-lagged design is a methodological strength, there are limitations associated with its use. For instance, not all participants completed the survey at both time points. Further, we used shortened versions of some scales, and all variables were derived from self-report measures, raising concerns of common method variance. However, established recommendations for controlling for the influence of common method bias were followed (Podsakoff et al., 2003) and the statistical analyses revealed that common method variance did not wholly explain the associations in the data. Future research should employ the full items from established scales, and use non self-report data to mitigate these concerns.

Another potential limitation is our ability to generalise to the broader organisation from which the sample was drawn. Although the HRM manager assured us that the three divisions resemble other parts of the business, we cannot confidently make this claim because we are not privy to the data. Our model may also generalise less well in occupations or organisations in which employees are not faced with exhausting types of work, as there may 
be a restriction of range on emotional exhaustion. Moreover, our results may not be generalisable to other sectors or countries.

\section{Practical Implications}

Organisations ought to consider how they communicate the intent of the HRM practices that they administer because employees' interpretation of the underlying motive impacts employee wellbeing. If employees perceive that HRM practices are meant to reduce costs - regardless of the organisation's actual intentions - employees experience increased workload and emotional exhaustion. Hence, to reduce emotional exhaustion, organisations should communicate that HRM practices are intended to promote employee effectiveness.

Does this imply that organisations should only communicate that the HRM policies and practices are designed to increase employee performance, and never to reduce costs? Doing so is probably unwise for at least three reasons. First, organisations (at least to some extent) must design HRM policies and practices to enhance employee performance while keeping an eye on costs in order to remain financially competitive in the marketplace. Employees are likely cognizant of this, and will respect their organisation when leadership is honest with the intentions behind policies and practices (Cartwright and Holmes, 2006). Second, our study does not include productivity or other financial variables and thus the commercial benefits to organisations are not reported. It may be that employees who attribute HRM policies and practices to cost containment, and who are overloaded at work, are higher performers, at least in the short-term; the relationship between HRM-attributions and employee performance may therefore not be straightforward. Third, the extent to which organisations communicate that HRM policies and practices are intended to support employee performance may be limited by the strategic value of the role-holders (Lepak and Snell, 1999). 
Our research also suggests that HRM practitioners should focus on finding ways to promote job involvement, for example by increasing employee participation in decisionmaking (Brown, 1996). However, caution should be exercised as excessive levels of job involvement may have unintended consequences (e.g. Snir and Harpaz, 2012).

\section{Conclusion}

Our theoretical model and results point to the criticality of examining "the why" of HRM practices. When employees believe that HRM practices are designed to enhance their job performance, they become more involved in their job, and experience decreasing levels of emotional exhaustion. Conversely, when they believe that HRM practices are designed to reduce organisational costs, they report that their workload is burdensome, and experience heightened emotional exhaustion. Hence, it may behove HRM practitioners to understand employee attributions of HRM policies and practices, develop a strategy for how they wish the policies and practices to be viewed by employees, and ensure that the HRM policies and practices communicate their intended message. 


\section{References}

Alfes, K., Shantz, A. and Truss, C. (2012). 'The link between perceived HRM practices, performance and well-being: the moderating effect of trust in the employer'. Human Resource Management Journal, 22: 4, 409-427.

Arbuckle, J. L. (2006). 'AMOS' (Version 7.0) [Computer Program]. Chicago, SPSS.

Baron, R. and Kenny, D. (1986). 'The moderator-mediator variable distinction in social psychological research: conceptual, strategic, and statistical considerations'. Journal of Personality and Social Psychology, 51: 6, 1173-1182.

Becker, T. (2005). 'Potential problems in the statistical control of variables in organizational research: a qualitative analysis with recommendations'. Organizational Research Methods, 8: 3, 274-289.

Beehr, T., Walsh, J. and Taber, T. (1976). 'Relationships of stress to individually and organizationally valued states: higher order needs as a moderator'. Journal of Applied Psychology, 61: 1, 41-47.

Bentler, P. M. (1990). 'Comparative fit indexes in structural models'. Psychological Bulletin, 107, 2: 238-246.

Bollen, K. A. (1989). 'A new incremental fit index for general structural equation models'. Sociological Methods \& Research, 17, 3: 303-316.

Bos-Nehles, A. C., Van Riemsdijk, M. J. and Kees Looise, J. (2013). 'Employee perceptions of line management performance: applying the AMO theory to explain the effectiveness of line managers' HRM implementation'. Human Resource Management, 52: 861-877.

Boxall, P. and Macky, K. (2009). 'Research and theory on high-performance work systems: Progressing the high-involvement stream'. Human Resource Management Journal, 19: 1, $3-23$. 
Brown, S. (1996). 'A meta-analysis and review of organizational research on job involvement'. Psychological Bulletin, 120: 2, 235-255.

Brown, S. and Leigh, T. W. (1996). 'A new look at psychological climate and its relationship to job involvement, effort, and performance'. Journal of Applied Psychology, 81, 4: $358-368$.

Burke, R., Singh, P. and Fiksenbaum, L. (2010). 'Work intensity: potential antecedents and consequences'. Personnel Review, 39: 3, 347-360.

Cartwright, S. and Holmes, N. (2006). 'The meaning of work: the challenge of regaining employee engagement and reducing cynicism'. Human Resource Management Review, 16: 2, 199-208.

Chen, C. and Chiu, S. (2009). 'The mediating role of job involvement in the relationship between job characteristics and organizational citizenship behavior'. Journal of Social Psychology, 149: 4, 474-494.

Cook, T. and Campbell, D. (1979). Quasi-Experimental Design: Design and Analysis Issues for Field Settings, Skokie: Rand McNally.

Cropanzano, R., Rupp, D. and Byrne, Z. (2003). 'The relationship of emotional exhaustion to work attitudes, job performance, and organizational citizenship behaviors'. Journal of Applied Psychology, 88: 1, 160-169.

Den Hartog, D.N., Boselie, P. and Paauwe, J. (2004), 'Performance management: a model and research agenda'. Applied Psychology: An International Review, 53: 4, 556-569.

Elloy D., Everett J. and Flynn, W. (1991). 'An examination of the correlates of job involvement'. Group and Organization Management, 6: 2, 160-177. 
Folger, R. and Skarlicki, D. (1998). 'A popcorn metaphor for employee aggression', in R. Griffin, A. O’Leary-Kelly and J. Collins (eds), Dysfunctional Behavior in Organizations, Stamford: JAI Press.

Fontinha, R., Chambel, M. and De Cuyper, N. (2012). 'HR attributions and the dual commitment of outsourced IT workers'. Personnel Review, 41: 6, 832-848.

Godard, J. (2004). 'A critical assessment of the high performance paradigm'. British Journal of Industrial Relations, 42: 2, 349-378.

Godard, J. (2010). 'What is best for workers? The implications of workplace and human resource management practices revisited'. Industrial Relations, 49: 3, 466-488.

Gorgievski, M. and Hobfoll, S. (2008). 'Work can burn us out or fire us up: conservation of resources in burnout and engagement', in J. Halbesleben (ed.), Handbook of Stress and Burnout in Healthcare, New York: Nova Science Publishers.

Graen, G. B. and Uhl-Bien, M. (1995). 'Relationship-based approach to leadership: development of leader-member exchange theory of leadership over 25 years: applying a multi-level multi-domain perspective'. The Leadership Quarterly, 6: 2, 219-247.

Grandey, A., Dickter, D. and Sin, H. (2004). 'The customer is not always right: customer aggression and emotion regulation of service employees'. Journal of Organizational Behavior, 25: 3, 397-418.

Grant, D., Christianson, M. and Price, R. (2007). 'Happiness, health, or relationships? Managerial practices and employee well-being tradeoffs'. Academy of Management Perspectives, 21: 3, 51-63.

Guest, D. (2002). 'Human resource management, corporate performance and employee wellbeing: building the worker into HRM'. The Journal of Industrial Relations, 44: 3, $335-358$. 
Guest, D. and Bos-Nehles, A. (2013). 'Human resource management and performance: the role of effective implementation', in J. Paauwe, D. Guest, and P. M. Wright (eds.), Human Resource Management and Performance, Chichester, Sussex: Wiley.

Guest, D. and Peccei, R. (2001). 'Partnership at work: mutuality and the balance of advantage'. British Journal of Industrial Relations, 39: 2, 207-236.

Hair, J. F., Black, W. C., Babin, B. J. and Anderson, R. E. (2009). Multivariate data analysis. New Jersey: Pearson Prentice Hall.

Harley, B., Allen, B. and Sargent, L. (2007). 'High performance work systems and employee experience of work in the service sector'. British Journal of Industrial Relations, 45: 3, $607-633$.

Hassan, S. (2012). 'Sources of professional employees' job involvement: an empirical assessment in a government agency'. Review of Public Personnel Administration, 20: 10, $1-23$.

Hayes, A. (2013). An Introduction to Mediation, Moderation, and Conditional Process Analysis: A Regression-based Approach, Guildford: Guildford Press.

Heider, F. (1958). The Psychology of Interpersonal Relations, London: Wiley.

Hobfoll, S. (1989). 'Conservation of resources: a new attempt at conceptualising stress'. American Psychologist, 44: 3, 513-524.

Hobfoll, S. and Freedy, J. (1993). 'Conservation of resources: a general stress theory applied to burnout', in W. Schaufeli, C. Maslach and T. Marek (eds), Professional Burnout: Recent Developments in Theory and Research, Philadelphia: Taylor and Francis.

Holman, D., Chissick, C. and Totterdell, P. (2002). 'The effects of performance monitoring on emotional labor and well-being in call centers'. Motivation and Emotion, 26: 1, 5781. 
Hu, L. and Bentler, P. M. (1998). 'Fit indices in covariance structure modeling: sensitivity to underparameterized model misspecification.' Psychological Methods, 3, 4: 424-453.

Hu, L. and Bentler, P. M. (1999). 'Cutoff criteria for fit indexes in covariance structure analysis: Conventional criteria versus new alternatives'. Structural Equation Modeling, 6: $1-55$.

Hülsheger, U., Alberts, H., Feinholdt, A. and Lang, J. (2013). 'Benefits of mindfulness at work: the role of mindfulness in emotion regulation, emotional exhaustion, and job satisfaction'. Journal of Applied Psychology, 98: 2, 310-325.

Jensen, J., Patel, P. and Messersmith, J. (2013). 'High-performance work systems and job control: consequences for anxiety, role overload, and turnover intentions?'. Journal of Management, 39: 6, 1699-1724.

Judge, T., Bono, J. and Locke, E. (2000). 'Personality and job satisfaction: the mediating role of job characteristics'. Journal of Applied Psychology, 85: 2, 237-249.

Kalmi, P. and Kauhanen, A. (2008). 'Workplace innovations and employee outcomes: evidence from Finland'. Industrial Relations: A Journal of Economy and Society, 47: 3, $430-459$.

Kelliher, C. and Anderson, D. (2010). 'Doing more with less? Flexible working practices and the overload of work'. Human Relations, 63: 1, 83-106.

Kenworthy, J., Fay, C., Frame, M. and Petree, R. (2014). 'A meta-analytic review of the relationship between emotional dissonance and emotional exhaustion'. Journal of Applied Social Psychology, 44: 2, 94-105.

Kinnie, N., Hutchinson, S., Purcell, J., Rayton, B. and Swart, J. (2005). 'Satisfaction with HR practices and commitment to the organisation: why one size does not fit all'. Human Resource Management Journal, 15: 4, 9-29. 
Kooij, D., Jansen, P., Dikkers, J. and De Lange, A. (2010). 'The influence of age on the associations between HR practices and both affective commitment and job satisfaction: a meta-analysis'. Journal of Organizational Behavior, 31: 8, 1111-1136.

Landsbergis, P., Cahill, J. and Schnall, P. (1999). 'The impact of lean production and related new systems of work organization on worker health'. Journal of Occupational Health Psychology, 4: 2, 108-130.

Lee, R. T. and Ashforth, B. E. (1996). 'A meta-analytic examination of the correlates of the three dimensions of job burnout'. Journal of Applied Psychology, 81: 2, 123-133.

Lindert, J., Müller-Nordhorn, J. and Soares, J. (2009). 'Age and distress of women: results of a representative population-based study'. Archives of Women's Mental Health, 12: 3, $173-181$.

Lodahl, T. and Kejner, M. (1965). 'The definition and measurement of job involvement'. Journal of Applied Psychology, 49: 1, 24-33.

MacCallum, R. C., Browne, M. W. and Sugawara, H. M. (1996). 'Power analysis and determination of sample size for covariance structure modeling'. Psychological Methods, 1, 2: 130-149.

Macky, K. and Boxall, P. (2007). 'The relationship between 'high-performance work practices' and employee attitudes: an investigation of additive and interaction effects'. The International Journal of Human Resource Management, 18: 4, 537-567.

Macky, K. and Boxall, P. (2008). 'High-involvement work processes, work overload and employee well-being: a study of New Zealand worker experiences'. Asia Pacific Journal of Human Resources, 46: 1, 38-55.

Marsh, H. W. and Hau, K. T. (1996). 'Assessing goodness of fit: is patrimony always desirable?'. Journal of Experimental Education, 64: 4, 364. 
Maslach, C. and Jackson, S. (1981). 'The measurement of experienced burnout'. Journal of Organizational Behavior, 2: 2, 99-113.

Maslach, C., Schaufeli, W. and Leiter, M. (2001). 'Job burnout'. Annual Review of Psychology, 52: 1, 397-422.

Maurer, T., Weiss, E. and Barbeite, F. (2003). 'A model of involvement in work-related learning and development activity: the effects of individual, situational, motivational, and age variables'. Journal of Applied Psychology, 88: 4, 707-724.

Mignonac, K. and Richebé, N. (2013). “'No strings attached?’: how attribution of disinterested support affects employee retention'. Human Resource Management Journal, 23: 1, 72-90.

Morin, A., Vandenberghe, C., Turmel, M., Madore, I. and Maïano, C. (2013). 'Probing into commitment's nonlinear relationships to work outcomes'. Journal of Managerial Psychology, 28: 2, 202-223.

Moore, J. (2000). 'Why is this happening? A causal attribution approach to work exhaustion consequences'. Academy of Management Review, 25: 2, 335-349.

Nishii, L. H., Lepak, D. and Schneider, B. (2008). 'Employee attributions of the "why" of HR practices: their effects on employee attitudes and behaviors and customer satisfaction'. Personnel Psychology, 61: 3, 503-545.

Oxenbridge, S. and Moensted, M. (2011). 'The relationship between payment systems, work overload and health and safety outcomes'. Policy and Practice in Health and Safety, 9: 2, $7-26$.

Paauwe, J. and Boselie, P. (2003). 'Challenging 'strategic HRM' and the relevance of the institutional setting'. Human Resource Management Journal, 13: 3, 56-70. 
Paoline, E. and Lambert, E. (2011). 'Exploring potential consequences of job involvement in jail staff’. Criminal Justice Policy Review, 20: 10, 1-23.

Parasuraman, S. and Alutto, J. A. (1984). 'Sources and outcomes of stress in organizational settings: Toward the development of a structural model'. The Academy of Management Journal, 27, 2: 330-350.

Piening, E., Baluch, A. and Salge, T. (2013). 'The relationship between employees' perceptions of human resource systems and organizational performance: examining mediating mechanisms and temporal dynamics'. Journal of Applied Psychology, 98: 6, 926-947.

Piening, E., Baluch, A. and Ridder, H. (2014). 'Mind the intended-implemented gap: understanding employees' perceptions of HRM'. Human Resource Management, 53: 4, $545-567$.

Podsakoff, P., MacKenzie, S., Jeong-Yeon, L. and Podsakoff, N. (2003). 'Common method biases in behavioral research: a critical review of the literature and recommended remedies'. Journal of Applied Psychology, 88: 5, 879-903.

Podsakoff, N., LePine, J. and LePine, M. (2007). 'Differential challenge stressor-hindrance stressor relationships with job attitudes, turnover intentions, turnover, and withdrawal behaviour: a meta-analysis'. Journal of Applied Psychology, 92: 2, 438-454.

Purcell, J. (1999). 'Best practice and best fit: Chimera or cul-de-sac?' Human Resource Management Journal, 9: 3, 26-41.

Purcell, J. and Hutchinson, S. (2007). 'Front-line managers as agents in the HRMperformance causal chain: theory, analysis and evidence'. Human Resource Management Journal, 17: 3-20.

Reddy, S. (1992). 'Effects of ignoring correlated measurement error in structural equation models'. Educational and Psychological Measurement, 52: 3, 549-570. 
Snir, R. and Harpaz, I. (2012). 'Beyond workaholism: towards a general model of heavy work investment'. Human Resource Management Review, 22: 3, 232-243.

Sprigg, C. and Jackson, P. (2006). 'Call centers as lean service environments: job-related strain and the mediating role of work design'. Journal of Occupational Health Psychology, 11: 2, 197-212.

Truss, C., Shantz, A., Soane, E., Alfes, K. and Delbridge, R. (2013). 'Employee engagement, organizational performance and individual well-being: exploring the evidence, developing the theory'. The International Journal of Human Resource Management, 24: $14,2657-2669$.

Van Buren, H., Greenwood, M. and Sheehan, C. (2011). 'Strategic human resource management and the decline of employee focus'. Human Resource Management Review, 21: 3, 209-219.

Van De Voorde, K., Paauwe, J. and Van Veldhoven, M. (2012). 'Employee well-being and the HRM-organizational performance relationship: a review of quantitative studies'. International Journal of Management Reviews, 14: 4, 391-407.

Whetten, D. (1989). 'What constitutes a theoretical contribution?'. Academy of Management Review, 14: 4, 490-495.

White, M., Hill, S. and McGovern, P. (2003). 'High performance management practices, working hours and work-life balance'. British Journal of Industrial Relations, 41: 2, $175-195$.

Wright, T. and Bonett, D. (1997). 'The role of pleasantness and activation-based well-being in performance prediction'. Journal of Occupational Health Psychology, 2: 3, 212-219.

Wright, P., Snell, S. and Dyer, L. (2005). 'New models of strategic HRM in a global context'. The International Journal of Human Resource Management, 16: 6, 875-881. 
TABLE 1

Means, Standard Deviations, Intercorrelations, and Scale Reliabilities

\begin{tabular}{|c|c|c|c|c|c|c|c|c|c|c|c|c|}
\hline & $\begin{array}{c}\mathrm{M} \\
(\mathrm{SD})\end{array}$ & 1 & 2 & 3 & 4 & 5 & 6 & 7 & 8 & 9 & 10 & 11 \\
\hline 1. Gender & -- & - & & & & & & & & & & \\
\hline \multirow[t]{2}{*}{ 2. Age } & 42.00 & -.15 & -- & & & & & & & & & \\
\hline & (15.64) & & & & & & & & & & & \\
\hline 3. Manager & -- & .11 & .09 & -- & & & & & & & & \\
\hline 4. Division A & -- & $.62 * *$ & -.15 & -.05 & -- & & & & & & & \\
\hline 5. Division B & -- & -.07 & .05 & .13 & $-.48 * *$ & -- & & & & & & \\
\hline 6. Division $\mathrm{C}$ & -- & $-.44 * *$ & .07 & -.10 & $-.33 * *$ & $-.67 * *$ & -- & & & & & \\
\hline 7. HRM-performance & 4.55 & $.18 *$ & .13 & -.13 & .10 & -.08 & -.01 & $(.81)$ & & & & \\
\hline Attribution & $(1.01)$ & & & & & & & & & & & \\
\hline 8. HRM-cost & 4.07 & $.30 * *$ & -.04 & $.15^{*}$ & $.26 * *$ & -.03 & $-.19 *$ & .03 & $(.81)$ & & & \\
\hline Attribution & $(1.04)$ & & & & & & & & & & & \\
\hline \multirow[t]{2}{*}{ 9. Job Involvement } & 5.41 & -.05 & $.19 *$ & -.06 & .05 & -.06 & .03 & $.33 * *$ & .03 & $(.93)$ & & \\
\hline & $(1.25)$ & & & & & & & & & & & \\
\hline \multirow[t]{2}{*}{ 10. Work Overload } & 3.74 & .01 & -.06 & -.01 & $.15^{*}$ & $.15^{*}$ & .04 & -.09 & .14 & $-.15^{*}$ & $(.82)$ & \\
\hline & $(1.00)$ & & & & & & & & & & & \\
\hline 11. Emotional & 3.47 & -.04 & $-.17 *$ & .01 & .02 & .02 & -.04 & $-.20 * *$ & .01 & $-.36 * *$ & $.46^{* *}$ & $(.89)$ \\
\hline Exhaustion & (1.37) & & & & & & & & & & & \\
\hline
\end{tabular}

Notes: $\mathrm{n}=180$; Cronbach Alpha coefficients are on the diagonal; $\mathrm{M}=\mathrm{Mean} ; \mathrm{SD}=$ Standard Deviation; ${ }^{*} p<.05 ; * * p<.01$ 
TABLE 2

Fit Statistics from Measurement Model Comparison

\begin{tabular}{|c|c|c|c|c|c|c|c|}
\hline Models & $\chi^{2}(\mathrm{df})$ & CFI & IFI & RMSEA & SRMR & $\chi_{\text {diff }}^{2}$ & $\overline{\mathrm{df}_{\text {diff }}}$ \\
\hline Full measurement model & $601(337)$ & .903 & .904 & .066 & .077 & & \\
\hline Model $\mathrm{A}^{\mathrm{a}}$ & $815(341)$ & .826 & .828 & .088 & .104 & 214 & $4 * * *$ \\
\hline Model $\mathrm{B}^{\mathrm{b}}$ & $901(341)$ & .794 & .796 & .096 & .104 & 300 & $4 * * *$ \\
\hline Model C $C^{c}$ & $727(341)$ & .858 & .860 & .080 & .086 & 126 & $4 * * *$ \\
\hline Model $\mathrm{D}^{\mathrm{d}}$ & $1093(344)$ & .724 & .728 & .110 & .116 & 492 & $7 * * *$ \\
\hline $\begin{array}{l}\text { Model E } \\
\text { (Harman's single-factor test) }\end{array}$ & $1624(347)$ & .530 & .535 & .143 & .150 & 1023 & $10 * * *$ \\
\hline
\end{tabular}

Notes: $\mathrm{n}=180, * * * \mathrm{p}<.001 ; \chi^{2}=$ chi-square discrepancy, $\mathrm{df}=$ degrees of freedom; CFI=Comparative Fit Index; IFI=Incremental Fit Index; RMSEA=Root Mean Square Error of Approximation; SRMR=Standardised Root Mean Square Residual; $\chi_{\text {diff }}^{2}=$ difference in chi-square, df diff $_{\text {difference in degrees of freedom; in all }}$ measurement models, error terms were free to covary between two pairs of job involvement and one pair of work overload items to improve fit and help reduce bias in the estimated parameter values (Reddy 1992). All models are compared to the full measurement model.

${ }^{a}=$ Job involvement and work overload combined into one factor

$\mathrm{b}=$ Job involvement and emotional exhaustion combined into one factor

${ }^{c}=$ Work overload and emotional exhaustion combined into one factor

$\mathrm{d}=$ Job involvement, work overload and emotional exhaustion combined into one factor

$\mathrm{e}=\mathrm{All}$ constructs combined into one factor 
TABLE 3

Test of Parallel Mediation of Job Involvement $\left(M_{1}\right)$ and Work Overload $\left(M_{2}\right)$ on the HRM-performance Attribution-Emotional Exhaustion Relationship

\begin{tabular}{|c|c|c|c|c|c|c|c|c|c|c|}
\hline & \multicolumn{2}{|c|}{$M_{1}$ Job Involvement } & \multicolumn{2}{|c|}{$M_{2}$ Work Overload } & \multicolumn{6}{|c|}{ Emotional Exhaustion } \\
\hline & $B$ & $S E$ & $B$ & $S E$ & $B$ & $S E$ & $B$ & $S E$ & $B$ & $S E$ \\
\hline Gender & -.40 & .21 & -.24 & .18 & -.17 & .24 & -.37 & .22 & -.17 & .21 \\
\hline Age & .01 & .01 & -.01 & .01 & -.01 & .01 & -.01 & .01 & .01 & .01 \\
\hline Manager & .02 & .19 & .01 & .16 & -.10 & .22 & -.07 & .20 & -.10 & .18 \\
\hline Division A & .45 & .36 & .42 & .31 & .28 & .41 & .48 & .38 & .20 & .34 \\
\hline Division B & .02 & .22 & -.20 & .19 & .07 & .25 & .09 & .24 & .19 & .21 \\
\hline $\begin{array}{l}\text { Performance } \\
\text { Attribution }\end{array}$ & $.52 * *$ & .10 & -.12 & .09 & $-.29 * *$ & .11 & & & -.05 & .10 \\
\hline $\begin{array}{l}M_{1} \text { Job } \\
\text { Involvement }\end{array}$ & & & & & & & $-.42 * *$ & .08 & $-.34 * *$ & .08 \\
\hline $\begin{array}{l}M_{2} \text { Work } \\
\text { Overload }\end{array}$ & & & & & & & & & $.57 * *$ & .08 \\
\hline Constant & $2.67 * *$ & .61 & $4.51 * *$ & .52 & $5.48 * *$ & .69 & $6.28 * *$ & .59 & $3.83 * *$ & .74 \\
\hline$F$ statistic & \multicolumn{2}{|c|}{$6.15 * *$} & \multicolumn{2}{|c|}{1.54} & \multicolumn{2}{|c|}{$2.23 *$} & \multicolumn{2}{|c|}{$6.04 * *$} & \multicolumn{2}{|c|}{$10.80 * *$} \\
\hline$R^{2}$ & \multicolumn{2}{|c|}{.19} & \multicolumn{2}{|c|}{.06} & \multicolumn{2}{|c|}{.08} & \multicolumn{2}{|c|}{.10} & \multicolumn{2}{|c|}{.36} \\
\hline
\end{tabular}


TABLE 4

Test of Parallel Mediation of Job Involvement $\left(M_{1}\right)$ and Work Overload $\left(M_{2}\right)$ on the HRM-cost Attribution-Emotional Exhaustion Relationship

\begin{tabular}{|c|c|c|c|c|c|c|c|c|c|c|}
\hline & \multicolumn{2}{|c|}{$M_{1}$ Job Involvement } & \multicolumn{2}{|c|}{$M_{2}$ Work Overload } & \multicolumn{6}{|c|}{ Emotional Exhaustion } \\
\hline & $B$ & $S E$ & $B$ & $S E$ & $B$ & $S E$ & $B$ & $S E$ & $B$ & $S E$ \\
\hline Gender & -.24 & .23 & $-.34 *$ & .18 & -.28 & .24 & -.10 & ,21 & -.17 & .20 \\
\hline Age & $.01 *$ & .01 & $-.01 *$ & .01 & $-.02 *$ & .01 & -.01 & 01 & -.01 & .01 \\
\hline Manager & -.14 & .21 & -.02 & .16 & -.03 & .22 & -.05 & ,19 & -.06 & .18 \\
\hline Division A & .34 & .39 & .35 & .31 & .32 & .42 & .05 &, 37 & .24 & .34 \\
\hline Division B & -.02 & .24 & -.19 & .19 & .09 & .26 & .21 &, 22 & .20 & .21 \\
\hline $\begin{array}{l}\text { Cost } \\
\text { Attribution }\end{array}$ & .08 & .11 & $.17^{*}$ & .08 & -.01 & .11 & & & -.08 & .09 \\
\hline $\begin{array}{l}M_{l} \text { Job } \\
\text { Involvement }\end{array}$ & & & & & & & & & $-.35 * *$ & .07 \\
\hline $\begin{array}{l}M_{2} \text { Work } \\
\text { Overload }\end{array}$ & & & & & & & $.64 * *$ & .10 & $.58 * *$ & .09 \\
\hline Constant & $4.74 * *$ & .56 & $3.43 * *$ & .45 & $4.18 * *$ & .60 & $1.65^{* *}$ & .57 & $3.84 * *$ & .70 \\
\hline$F$ statistic & & & & & & & & & & \\
\hline$R^{2}$ & & & & & & & & & & \\
\hline
\end{tabular}


FIGURE 1

HRM Attributions and Emotional Exhaustion Model

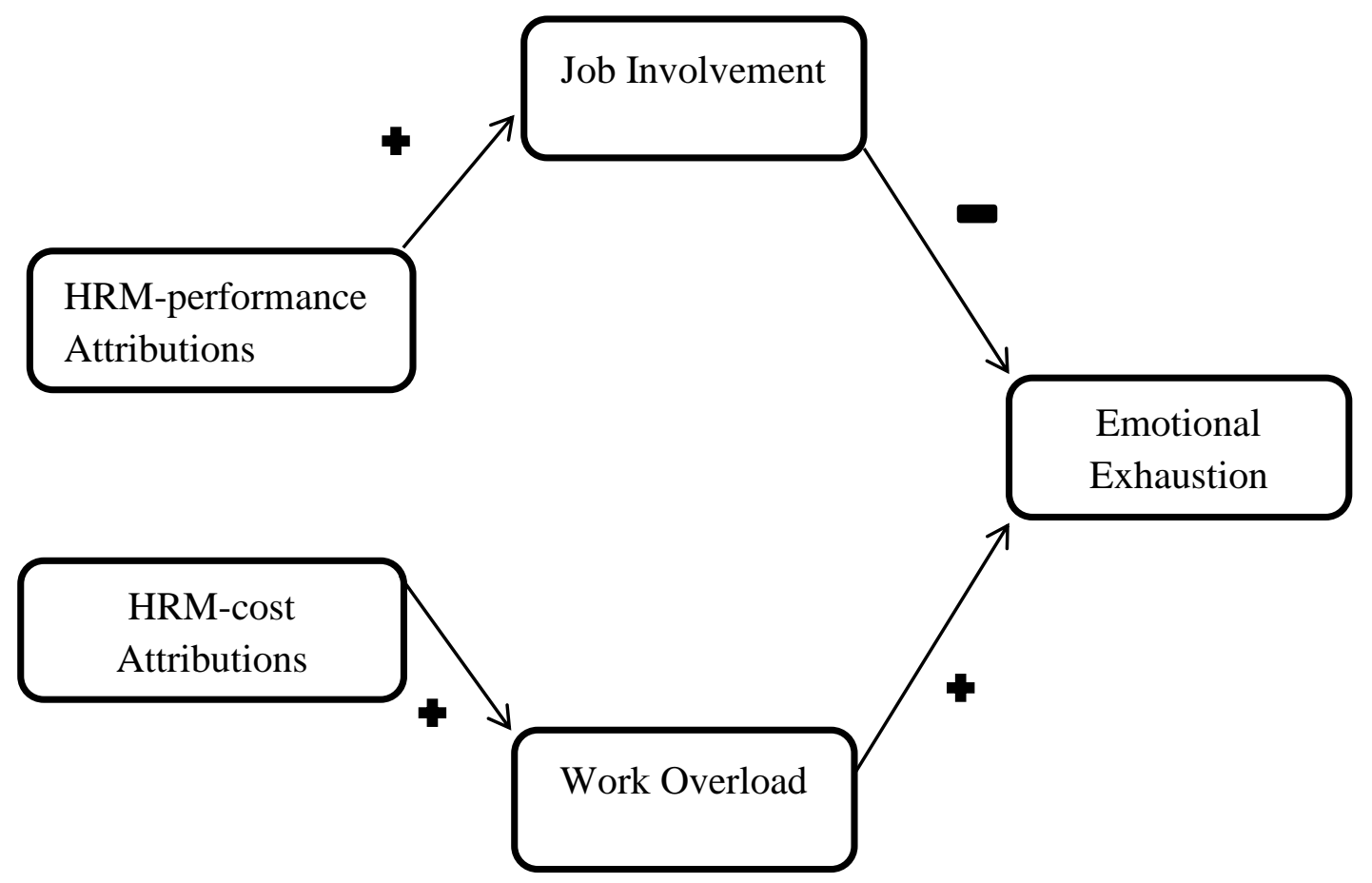




\section{Appendix 1}

To what extent do you agree or disagree with each of the following statements:

\section{HRM-performance Attributions}

1. Training and development in my organisation are designed to maximise employees' performance

2. Reward systems in my organisation are designed to maximise employees' performance

3. The selection process in my organisation is designed to maximise employees' performance

4. The performance appraisal process in my organisation is designed to maximise employees' performance

5. Employee participation is designed to maximise employees' performance

\section{HRM-cost Attributions}

6. Training and development in my organisation are designed to keep costs down

7. Reward systems in my organisation are designed to keep costs down

8. The selection process in my organisation is designed to keep costs down

9. The performance appraisal process in my organisation is designed to keep costs down

10. Employee participation is designed to keep costs down

\section{Job Involvement}

11. I enjoy my work

12. Facing my daily tasks is a painful and boring experience (R)

13. Work to me is more like a chore or burden (R)

14. I get carried away when I'm working

15. I spend time thinking about how to do my job better

16. I feel connected to the events in my workplace

17. I used to be more ambitious about my work than I am now (R)

18. I used to care more about my work, but now other things are more important to me (R)

19. Quite often I feel like staying home from work instead of coming in (R)

\section{Work Overload}

20. I am given enough time to do what is expected of me on my job (R)

21. It often seems like I have too much work for one person to do

22. The performance standards on my job are too high

23. I never seem to have enough time to get everything done in my job

24. To get ahead in the organisation, employees are expected to work more than their contracted hours each week

25. Employees are often expected to work overtime or take work home at night and/or weekends

\section{Emotional Exhaustion}

26. I feel emotionally drained from my work

27. I feel used up at the end of the workday

28. I feel burned out from my work 